\title{
A PERSPECTIVA DAS MEDIAÇÕES NA COMUNICAÇ̃O E DESENVOLVIMENTO (COMDES): UM NOVO MAPA E SEU USO NA ANÁLISE DE UMA REALIDADE RURAL
}

\author{
Ana Carolina D. Escosteguy* \\ Angela Cristina Trevisan Felippi**
}

RESUMO

O capítulo recupera uma proposta para o estudo das mediações em realidades rurais, apresentando o Mapa de Chaves Teórico-Analiticas para um Estudo Socioantropológico de TICs, construído a partir da teoria das mediações de Jesús Martín-Barbero. O mapa é processo e resultado de pesquisa realizada numa região do Sul do Brasil, que investigou as relações entre os sujeitos da agricultura familiar e as Tecnologias de Informação e Comunicação. A pesquisa interdisciplinar e interinstitucional, concluída em 2018, evidenciou na realidade rural regional as mediações da institucionalidade, socialidade, tecnicidade, ritualidade, mobilidade, espacialidade e temporalidade, circunscritas num "entorno tecnocomunicativo", identificado por Marín-Barbero em texto recente. Como síntese conclusiva aponta-se a compreensão de uma certa ruralidade, na qual a comunicação por meio das TIC tem centralidade, porém não resume a vida social. Palavras-chave: Mediações; Jesús Martín-Barbero; Comunicação e Desenvolvimento; Tecnologias de Comunicação; Desenvolvimento Regional.

\section{INTRODUÇÃO}

A obra de Jesús Martín-Barbero exerceu notória influência na pesquisa em Comunicação, não só no Brasil e na região ibero-americana, mas também em quadrantes de língua inglesa ${ }^{1}$. Seu legado transcende ainda a área da Comunicação, exercendo, por exemplo, influência em áreas que se dedicam ao

\footnotetext{
* http://orcid.org/0000-0002-0361-6404. http://www.ufrgs.br . Universidade Federal do Rio Grande do Sul. Professora Visitante do Programa de Pós-Graduaçao em Comunicaçao UFRGS; Pesquisadora CNPQ. carolad2017@gmail.com .

** https://orcid.org/0000-0003-3545-0215 http://www.unisc.br. Universidade de Santa Cruz do Sul. Professora dos programas de pós-graduação em Desenvolvimento Regional e em Letras. Professora das graduações em Comunicação Social - Universidade de Santa Cruz do Sul. Líder do Grupo de Pesquisa do CNPq Desenvolvimento Regional e Processos Socioculturais. angelafe@unisc.br.

1 Ver, por exemplo, a reflexão de Nick Couldry em Matrizes, vol 12 (1), 2018
} 
estudo do desenvolvimento das sociedades, em especial no subcontinente ${ }^{2}$. Sua recente partida nos motiva homenageá-lo, recuperando parte de suas contribuições que foram fundamentais na pesquisa, publicada em As tecnologias de comunicação no cotidiano de famílias rurais - $(\mathrm{Re})$ Configurações de uma ruralidade (EDUNISC, 2019), onde as áreas de Comunicação e de Desenvolvimento Regional estiveram integradas.

Nosso propósito, então, está centrado na apresentação do Mapa de Chaves Teórico-Analiticas para um Estudo Socioantropológico de TICs (ESCOSTEGUY, FELIPPI et al, 2019) que foi construído a partir da teoria das mediações, levando em conta principalmente o Mapa das Mediações Comunicativas da Cultura (Martín-Barbero, 2003) e o Mapa das Mutações Comunicativas e Culturais, proposto por Martín-Barbero, em 2009 (Moura, 2009). De modo articulado a tal exposição, recuperamos também algumas conclusões mais gerais da pesquisa que evidenciam o acionamento de nossa proposta.

É importante esclarecer ainda que produzimos uma combinação entre os dois mapas recém mencionados, fazendo um uso parcial de cada um deles. A implementação da proposta barberiana na pesquisa empírica depende da estratégia metodológica que se adote, por isso, "a escolha pode recair em determinadas mediações, e não em outras, dependendo do destaque que ganham na abordagem analítica" (LOPES, 2014, p.75). Isso significa que tanto um mapa como o outro podem ser utilizados de modo integral ou em parte. Portanto, extraímos do Mapa das Mediações Comunicativas da Cultura as seguintes chaves teórico-analíticas: a institucionalidade, a socialidade, a tecnicidade e a ritualidade; e do Mapa das Mutações Comunicativas e Culturais, a espacialidade, a temporalidade e a mobilidade. De nenhuma forma, desconhecemos o desafio que isso representa, mas optamos por encarar os riscos e ensaiar o uso desse novo mapa.

Por meio dessa proposição, efetivamos a transposição do trinômio original comunicação-cultura-política ${ }^{3}$ (MARTÍN-BARBERO, 2003) em dois pares: comunicação-cultura e política-sociedade, materializados, respectivamente, na problemática do entorno tecnocomunicativo e do desenvolvimento. A primeira indica que, por um lado, o centro das mudanças da sociedade contemporânea está situado no papel das tecnologias de comunicação que

\footnotetext{
Uma recuperação da presença da teoria das mediações no âmbito dos estudos de Desenvolvimento Regional pode ser encontrada em Felippi (2018).

3 Já no primeiro mapa das mediações, publicado em De los medios a las mediaciones (1987), consta esse tripé. Nossa tecitura teórica leva em conta três propostas do autor: a primeira de 1987; a segunda de 2003 onde a referência utilizada é o prefácio à quinta edição castelhana de De los medios a las mediaciones, traduzida para o português e publicada em 2003; e a terceira onde nossa principal referência é o mapa de 2009, publicado na Revista FAPESP (MOURA, 2009). As demais proposições, embora já em circulação (LOPES, 2018), não foram integradas em nossa trama teórico-analítica.
} 
passam a configurar um novo ecossistema comunicativo. Por outro, apesar da centralidade que adquire a tecnologia na atualidade, a vida social não fica reduzida às tecnologias que a constituem. Daí, a reivindicação de que as tecnologias são intrinsecamente sociais e, consequentemente, da relevância do protagonismo dos sujeitos.

Sobre a problemática do desenvolvimento que combina, de modo evidente, os termos política e sociedade, os esforços são no sentido de pensar a potência dos sujeitos diante das estruturas sociais, nas quais as tecnologias se inserem, para construírem futuros possíveis e emancipatórios. Contudo, observar os limites a que estes sujeitos estão circunscritos diante destas mesmas estruturas, numa realidade o modo como a tecnologia é ofertada à sociedade, carrega contraditoriamente a possibilidade de ampliação do poder de agência dos sujeitos, como os riscos de ampliação da dominação e da desigualdade social.

Dito isso, na sua integralidade, essa proposta foi sintetizada no diagrama que segue.

\section{MAPA DE CHAVES TEÓRICO-ANALÍTICAS \\ PARA UM ESTUDO SOCIOANTROPOLÓGICO DE TICs}

COMUNICAÇÃO / CULTURA

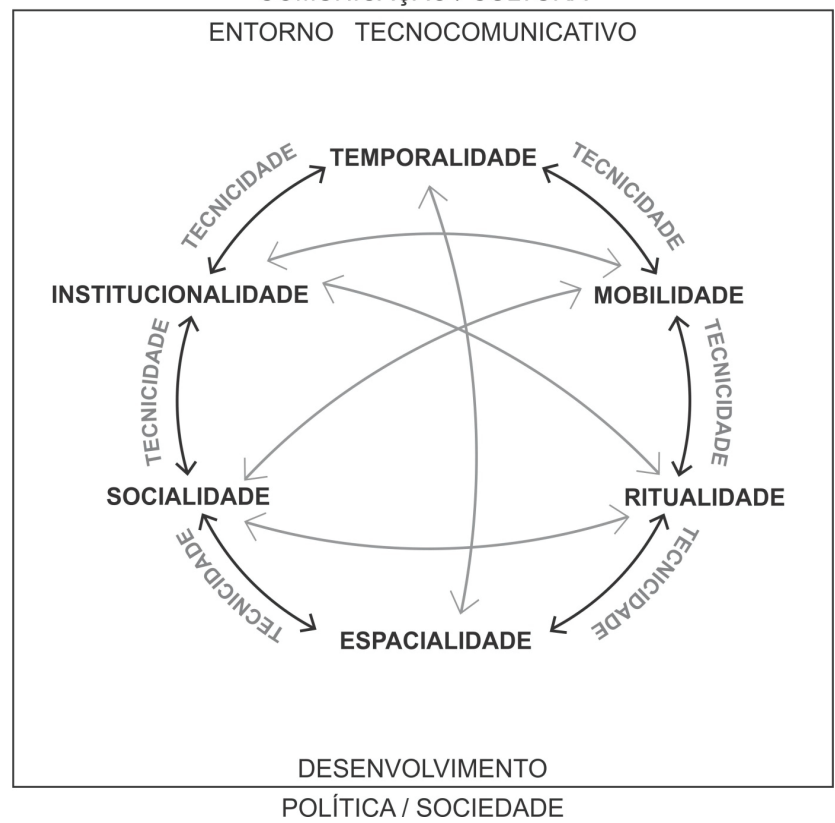

Figura 1: Mapa de chaves teórico-analíticas para um estudo socioantropológico de TICs 
O mapa resulta de pesquisa de caráter socioantropológico, desenvolvida na Microrregião de Santa Cruz do Sul ${ }^{4}$, no Rio Grande do Sul - Brasil entre os anos 2014 e 2018. A pesquisa, financiada pelo edital Universal MCTI/ CNPq $n^{\circ} 14 / 2014$, conduzida em rede integrando dois grupos de pesquisa do CNPq: Estudos e Projetos em Comunicação e Estudos Culturais (UFSM) e Desenvolvimento Regional e Processos Socioculturais (UNISC), tendo apoio da Pontifícia Universidade Católica do Rio Grande do Sul e da Universidade de Santa Cruz do Sul. A investigação envolveu duas áreas do conhecimento, a Comunicação e o Desenvolvimento Regional, alinhadas com os estudos de Comunicação e Desenvolvimento (CONDES). A pesquisa de campo foi realizada no município de Vale do Sol junto a sujeitos de sete famílias da agricultura familiar, relacionados à produção de tabaco e outras culturas.

\section{UM NOVO MAPA E SEU USO NA ANÁLISE DE UMA REALIDADE RURAL}

As Tecnologias de Informação e Comunicação (TICs) - compreendidas tanto como a mídia tradicional ${ }^{5}$ que engloba, entre outros meios, os jornais e revistas impressas, o rádio e a televisão, como a nova mídia, o telefone celular, o computador, os tablets e a própria internet - tornaram-se onipresentes na vida social contemporânea, portanto, tema central de inúmeras investigações, situadas em diferentes disciplinas e, consequentemente, fazendo uso de variadas perspectivas.

É no âmbito de uma visão de viés "construtivista" (QUIROZ; VELÉZ, 2014) que nos posicionamos na nossa investigação. No campo da comunicação, esse entendimento se coaduna com a compreensão de Silverstone et al (1996, p. 54) de que as tecnologias são tanto modeladoras quanto modeladas, o que constitui relações mútuas entre tecnologia, cultura e sociedade. A partir desse pressuposto, consideramos as TICs como artefatos que combinam uma dimensão material e simbólica.

Tomando esse entendimento como ponto de partida, no âmbito da pesquisa empírica, privilegiamos a compreensão dos usos, dos problemas, dos desafios que os indivíduos nos seus respectivos grupos sociais enfrentam

\footnotetext{
A Microrregião de Santa Cruz do Sul foi um recorte regional vigente a partir do IBGE e abriga os municípios Arroio do Tigre, Candelária, Estrela Velha, Gramado Xavier, Herveiras, Ibarama, Lagoa Bonita do Sul, Mato Leitão, Passa Sete, Santa Cruz do Sul, Segredo, Sinimbu, Sobradinho, Vale do Sol, Venâncio Aires, Vera Cruz.

5 Adota-se a terminologia de Dizard (2000) para facilitar a nomeação dos meios em subconjuntos diferentes.
} 
quando utilizam certas TICs, bem como a identificação de aspectos valorativos e representacionais postos em ação quando tais artefatos são adotados e adaptados por esses mesmos atores sociais nos seus respectivos contextos.

Embora os processos de comunicação contemporâneos, mediados tecnologicamente, simbolizem uma mudança cultural global no modo de vida dos indivíduos, mudança esta associada muitas vezes a um aparato tecnológico, também, difundido em nível global, nota-se, conjuntamente com esse, usos distintos, diferentes apropriações, interações e acessibilidades. Portanto, há uma condição temporal e espacial que deve ser levada em conta no estudo social da tecnologia.

Daí a pertinência de adotar, entre as chaves teórico-analíticas, as mediações da espacialidade e da temporalidade (MOURA, 2009). Essa preocupação atravessa o programa de pesquisa de Jesús Martín-Barbero. No final dos anos 1980, o autor chamava a atenção para a presença de novas tecnologias e a constituição de uma "nova etapa de aceleração da modernidade" latino-americana (JACKS; SCHMITZ, 2018, p. 120). Na ocasião, já indicava que abordar essas novas tecnologias na América Latina implicava em conhecer os "destiempos" ou a confluência da "multiplicidade de histórias, com seus próprios ritmos e com suas próprias lógicas (MARTÍN-BARBERO, 1995, p. 43). Ou seja, esse processo diz respeito à convivência entre uma cronologia das invenções tecnológicas, as narrativas de sua apropriação (modos de aquisição) e incorporação (usos) ou, ainda, "da compulsão por adquiri-las mesmo que, em muitos casos, não se tenha o que fazer com elas" (JACKS; SCHMITZ, 2018, p. 120). Isso reforça a pertinência da chave teórico-analítica da temporalidade.

Do mesmo modo, a mediação da espacialidade é central para a análise que estamos propondo. $\mathrm{O}$ autor reconhece o espaço como componente primordial dos processos sociais desde seu primeiro mapa das mediações. Em especial, quando aponta o bairro, a feira, a cidade como expressões da sociedade, onde ela se desenha e se manifesta com distintos contornos. $\mathrm{O}$ espaço, como "acumulação desigual do tempo" (SANTOS, 1996, p. 81), é consequência da história e está em permanente construção, não podendo ser pensado fora da sua relação com o tempo. Ou, como sumarizado por Edward Soja e apropriado em trabalhos anteriores (FELIPPI et al, 2019), a espacialidade como produto social, e a estruturação espaço-temporal da vida como definidora das ações sociais materialmente constituídas e concretizadas.

Recuperamos ainda de sua proposta de 2009 (MOURA, 2009) a mediação da mobilidade. Apesar de Martín-Barbero (2009a; 2018) salientar sua forte 
associação com a movimentação dos migrantes e seus impactos na cidade, no nosso caso, trata-se mais dos deslocamentos pendulares dos habitantes do campo ora física, ora virtualmente. $\mathrm{Na}$ primeira condição [mobilidade física], está, sobretudo, o êxodo da juventude rural, mas também o trânsito constante entre campo e cidade, bem como entre lar/localidade rural e escola/universidade/estágio/trabalhos temporários que se estendem cada vez mais pelo espaço. Na segunda [mobilidade virtual], a experiência da chegada das tecnologias digitais e da navegação virtual potencializam a vivência com imagens, informação, conhecimento, memórias, imaginários e de relações sociais nunca antes imaginadas.

Já do Mapa das Mediações Comunicativas da Cultura (MARTÍN-BARBERO, 2003) extraímos quatro mediações como chaves teórico-analíticas: a) a mediação da ritualidade, que diz respeito aos usos regulares e repetidos que se faz das tecnologias de comunicação - seja o celular, o computador, o jornal, a televisão -, para compreender como esses usos constituem rotinas, tanto no universo prático das famílias (relacionado à sua atividade laboral, seja na agricultura ou no espaço doméstico), quanto no seu universo simbólico (pertinente à sua cultura familiar); b) a socialidade, constituída por vivências das TICs pelas famílias agricultoras no meio rural, para perceber como seus sistemas de referências socioculturais configuram uma determinada ruralidade; c) a tecnicidade, entendida como o modo pelo qual os indivíduos se relacionam subjetivamente com os suportes e formatos, para apreender a constituição de suas competências com distintas linguagens e conteúdos; e, por fim, d) a institucionalidade, para detectar os regimes de regulação que adquirem força junto às famílias investigadas na apropriação e incorporação das TICs.

Tomando como eixos de análise a dimensão espaço-temporal dos processos sociais, afetada pela onipresença contemporânea das tecnologias de informação e comunicação, a temporalidade, espacialidade e tecnicidade são as mediações centrais da realidade estudada, se considerados os propósitos da pesquisa: compreender as interações cotidianas dos sujeitos com as tecnologias de comunicação, num certo espaço rural. Às três mediações principais, foram associadas as demais dispostas no mapa: mobilidade, ritualidade, socialidade e institucionalidade, com vistas à compreensão de uma ruralidade que se (re) configura pela ação dessas mesmas tecnologias. 


\section{MAPA DE CHAVES TEÓRICO-ANALÍTICAS PARA UM ESTUDO SOCIOANTROPOLÓGICO DE TICS - DESDOBRAMENTOS DAS MEDIAÇÕES EM UMA RURALIDADE DO SUL} COMUNICAÇÃO / CULTURA

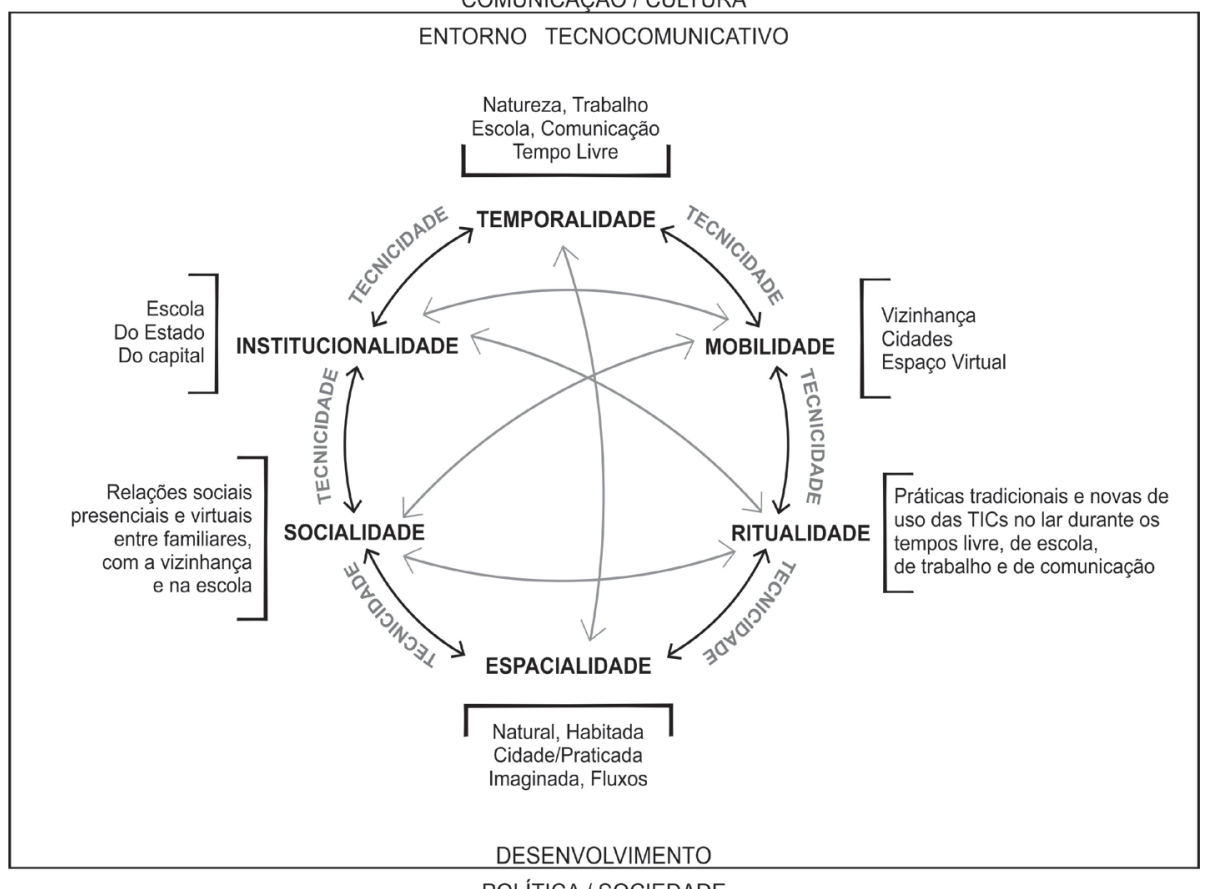

POLITICA / SOCIEDADE

Figura 2: Mapa de chaves teórico-analíticas para um estudo socioantropológico de TICs - Desdobramentos das mediações em uma ruralidade do Sul

\section{UMA SÍNTESE CONCLUSIVA}

De modo resumido, temos como conclusões da pesquisa a articulação entre espacialidade, temporalidade e tecnicidade no rural da Microrregião de Santa Cruz do Sul ${ }^{6}$ resulta numa certa ruralidade. Em outros termos, o exame de uma realidade local (singular), representada pelas famílias investigadas de Vale do Sol, na relação com a sua localização na Microrregião de Santa Cruz do Sul, que faz parte do território do tabaco, sendo esse, componente de um território mais amplo, o nacional, que, por sua vez, está em conexão com

\footnotetext{
${ }_{6}$ A região estudada é marcada social e culturalmente pela colonização germânica e, economicamente, caracterizada pela hegemonia da cadeia agroindustrial do tabaco, cuja produção da matéria prima, o tabaco, se organiza através da agricultura familiar. As tecnologias de comunicação estão presentes no rural sobretudo a partir da modernização do campo, sendo que a nova mídia, nosso interesse especial, é uma realidade de menos de dez anos.
} 
o globo, dão as coordenadas espaciais da dialética entre o local, o regional e o global que é resultado, assim como um vir a ser, de relações materiais e simbólicas deste espaço.

A constatação acima significa um reconhecimento da manutenção da força do espaço nos processos sociais. Via Milton Santos (1988; 1996), percebemos que, apesar da tendência à homogeneização movida pela globalização, como dito, a mesma não ocorre igualmente em todos os espaços, os locais reagem de forma distinta ao proposto pela verticalidade global. As diferenças, a que Santos atribui às condições históricas particulares dos espaços e à própria lógica global do sistema (de valorar mais certos espaços em relação a outros na exploração do capital), comprovam que o espaço não subsome à compressão do tempo. Com isso, reconhecemos que a Microrregião de Santa Cruz do Sul apresenta particularidades, inclusive na sua relação com as TICs. Particularidades que são as sínteses entre seu modo de vida, carregado de historicidade, e o que lhe é externo, resultados de processos sociais. O que, por sua vez, constitui também determinada ruralidade. Nossos achados corroboraram a literatura utilizada: apesar dos processos homogeneizadores da globalização que garantem a expansão global das invenções tecnológicas, indicando direções de uso, as experiências dos sujeitos com as tecnologias e os significados dados a elas guardam relação com os contextos e são espacialmente localizadas.

Tomando o mapa proposto pelo eixo temporalidade-espacialidade, constatamos que as famílias rurais pesquisadas estão sujeitas a múltiplas temporalidades e espacialidades. As principais temporalidades que fazem parte da organização do seu cotidiano identificadas foram as: da natureza, do trabalho, da escola, do tempo livre e da comunicação. E entre os distintos espaços que disputam a estruturação da vida dos sujeitos pesquisados, destacaram-se: o natural, o habitado/rural, o imaginado, o da cidade e o dos fluxos. Esses nos pareceram os mais influentes. A trama estabelecida entre as múltiplas temporalidades e múltiplas espacialidades, e delas com as demais mediações, com destaque para a tecnicidade, formam a ruralidade da Microrregião de Santa Cruz do Sul. Nas demais mediações, destacamos: a institucionalidade da escola, do capital (empresas do tabaco e das empresas de telecomunicações) e do Estado (regulação da mídia e telecomunicações), as socialidades típicas do mundo rural e novas que se desenham via os deslocamentos tanto físico, quanto virtual (pelo uso de TICs), as ritualidades, numa articulação entre práticas tradicionais e novas, a mobilidade física ou virtual, e, sobretudo, a tecnicidade relacionada ao manuseio, 
à competência e às habilidades com as tecnologias de comunicação, seja enquanto aparatos em si mesmos, seja por meio dos seus conteúdos. Sobretudo a tecnicidade nos interessa, tendo em vista que o fenômeno que nos detemos é a "compressão tempo-espaço" sob o aspecto da presença das tecnologias de comunicação no espaço rural da Microrregião e suas consequências.

No que diz respeito à tecnicidade, ressalva-se que essa ganha densidade, dado que no centro do mapa proposto uma das condições primordiais da nova configuração societária é o entorno tecnocomunicativo.

Contudo, em termos analíticos, observa-se uma distinção entre esse último e a tecnicidade. Para nós, o primeiro diz respeito à concretização da racionalidade de uma cultura e de um "modelo global de organização do poder", incrustado na estrutura social; a segunda trata de "organizadores perceptivos" (MARTÍN-BARBERO, 2003, p. 18), "operadores perceptivos e destrezas discursivas” (MARTÍN-BARBERO, 2018, p. 1877), isto é, vincula- se às práticas e às competências cotidianas dos sujeitos, permeadas pela incidência da matriz do novo ecossistema tecnocomunicativo.

Enfim, a utilização do Mapa de chaves teórico-analíticas para um estudo sócio-antropológico de TICs nos permitiu tratar das condições de facilitação e impedimento na apropriação de TICs; da convivência de múltiplos espaços (urbano/ rural/escola/casa/lavoura, entre outros) e tempos (do trabalho, livre, entretenimento, estudo); dos movimentos pendulares de deslocamento, seja físico ou virtual; dos rituais de incorporação das distintas tecnologias de comunicação; das relações sociais configuradas por esses mesmos artefatos, obviamente, situadas em uma determinada ruralidade. E, do modo mais abrangente, de referendar uma perspectiva de relações de coprodução entre tecnologia e sociedade.

\section{REFERÊENCIAS}

DIZARD, W. A nova mídia - A comunicação de massa na era da informação. Rio de Janeiro: Jorge Zahar, 2000.

ESCOSTEGUY, A. C.; FELIPPI, Â. C. T. et al. As tecnologias de comunicação no cotidiano de famílias rurais: (re) configurações de uma ruralidade. Santa Cruz do Sul: EDUNISC, 2019.

FELIPPI, Â. C. T.; SANCHEZ V., R.; SILVEIRA, R. L. L. da. La espacialidad en el Mapa Comunicativo de la Cultura: produto social y condición del devenir. In: JACKS, N.; SCHMITZ, D.; WOTTRICH, L.. Um nuevo mapa para invertigar la mutación cultural: Diálogo con la propuesta de Jesús Martín-Barbero. Quito: Ciespal, 2019, p. 91-116.

A referência original é o prefácio à edição de 1998, de De los medios a la mediaciones. Contudo, aqui preferimos citar artigo de Martín-Barbero que compila as três principais apresentações à sua obra. 
FELIPPI, Â. C. T.. As mediações de Jesús Martín-Barbero e os estudos de Comunicação no âmbito do Desenvolvimento Regional. Intexto, v. 4, p. 135-150, 2018.

LOPES, M. I. V. De Lopes. Mediação e recepção. Algumas conexões téoricas e metodológicas nos estudos latino-americanos de comunicação. Matrizes, vol 8 (1), jan./jun., p. 65-80, 2014.

LOPES, M. I. V. Teoria barberiana da comunicação. Matrizes, vol 12 (1), jan./abr., p. 39-63, 2018.

MARTÍN-BARBERO, J. América Latina e os anos recentes: o estudo da recepção em comunicação social. In Souza, M. W. (org.) Sujeito, o lado oculto do receptor. São Paulo: Brasiliense, 1995, p. 39-68.

MARTÍN-BARBERO, J. Pistas para entre-ver meios e mediações. Prefácio. In: Dos meios às mediações: comunicação, cultura e hegemonia. Rio de Janeiro, Ed. UFRJ, p. 11-21, 2003.

MARTÍN-BARBERO, J. Dos meios às mediações: 3 introduções. Matrizes, vol 12 (1), jan./abr., p. 9-31, 2018.

MOURA, M. Jesús Martín-Barbero: as formas mestiças da mídia. Entrevista com Jesús Martín-Barbero. Revista Pesquisa Fapesp, São Paulo, n. 163, p. 10-15, 2009.

QUIROZ, J.; VÉLEZ, S. Tecnología y sociedade: una aproximación a los estudios sociales de la tecnología. Revista CTS, n 26, vol. 9, maio de 2014, pp. 129-144.

SANTOS, Milton. Metamorfoses do espaço habitado: Fundamentos Teórico e metodológico da Geografia. São Paulo: Hucitec, 1988.

SANTOS, M. A natureza do espaço: técnica e tempo, razão e emoção. São Paulo: HUCITEC, 1996.

SILVERSTONE, R; HIRSCH, E.; MORLEY, D. Tecnologías de la información y de la comunicación y la economia moral de la família In Silverstone; Hirsch (eds) Los efectos de la nueva comunicación - El consumo de la moderna tecnologia en el hogar y en la família. Barcelona: Bosch, 1996, p. 39-57. 